\title{
Multiple paternity within the brood of single females of Loligo forbesi (Cephalopoda: Loliginidae), demonstrated with microsatellite DNA markers
}

\author{
P. W. Shaw*, P. R. Boyle \\ Department of Zoology, University of Aberdeen, AB9 2TN, Scotland, UK
}

\begin{abstract}
Microsatellite DNA markers developed for the squid Loligo forbesi were used to determine the genotype of a series of embryos obtained from egg strings of individual females. The results demonstrate that at least 2 males had been successful in fertilizing the eggs of a single female. The findings are compatible with observations of male competition at mating in other species of loliginid squid. They are discussed in relation to interpretation of specific questions of cephalopod ecology
\end{abstract}

KEY WORDS: Cephalopoda Squid $\cdot$ Loligo $\cdot$ Microsatellite DNA - Genotype - Mating

Squids of the family Loliginidae display a semelparous, approximately annual life-history strategy, with oviparity, high individual fecundity, no parental care of offspring and non-overlapping generations (Boyle 1990, Boyle \& Pierce 1994, Boyle \& Boletzky 1996). High inter-annual variability in population sizes are also commonly observed (Boyle \& Boletzky 1996). The common squid species of British coastal waters, Loligo forbesi, has typically complex population structures (Pierce et al. 1994) and recruitment patterns (Collins et al. 1997). From an individual perspective, such a semelparous lifestyle with uncertain recruitment can be predicted to result in the evolution of promiscuous mating strategies and the development of sperm competition (Parker 1970), or behaviours effecting the same result (Birkhead 1994).

Fertilization in cephalopods is invariably a process of paired matings in which packages of sperm (spermatophores) are transferred by a specially modified

\footnotetext{
- Present address: Department of Biological Sciences, University of Hull, Hull HU6 7RX, United Kingdom.

E-mail p.w.shaw@biosci.hull.ac.uk
}

male arm to a female, where they are retained by various species-specific means (Arnold 1984, Mangold 1987). In some loliginid species, underwater observations of behaviour at breeding have revealed complex mating strategies in which males of 2 distinct size classes compete to fertilize the spawning female. The female is paired with a large dominant male which guards her as she approaches the substratum to attach her finger-like egg strings. At this point in the process, a small 'sneaker' male (Archer 1988) may attempt to mate with the female. Such behaviour has been described for Loligo plej (F. P. DiMarco \& R. T. Hanlon unpubl. data in Hanlon \& Messenger 1996), Loligo vulgaris reynaudii (R. T. Hanlon, M. J. Smale \& W. H. H. Sauer unpubl. data in Hanlon \& Messenger 1996), and Loligo pealei (Hanlon 1996). To what extent, if any, the 'sneaker' male is successful in fertilising any eggs was unknown, this being difficult to assess under field conditions and given the sensitivity of squid to captivity. Molecular genetic markers have proven to be extremely informative in such situations in other animals, initially using multi-locus 'DNA fingerprinting' (e.g. Packer et al. 1991, Pemberton et al. 1992) and, more recently, single-locus microsatellite DNA markers (e.g. Morin et al. 1994, Estoup et al. 1995) to genetically determine paternities.

The present study uses genetic fingerprinting to indicate that multiple matings in a loliginid squid may result in multiple paternity of the offspring of a single female.

Methods. Two egg masses (A and B) of Loligo forbesi, each containing 10 to 15 strings of eggs, were obtained from shallow water $(<30 \mathrm{~m})$ off the west of Scotland near Kinlochbervie. Two single strings from each mass were fixed in separate bottles of $90 \%$ ethanol. Ten developing embryos from each string 
were dissected out and placed separately in $1.5 \mathrm{ml}$ of ethanol. Duplicate samples of the surface covering of each string were also fixed.

Total DVA was extracted from each embryo using a modified CTAB (2\% N-cetyl N,N,N-trimethylammonium bromide) extraction protocol optimised for squid tissue. Individual embryos were genotyped at each of 6 microsatellite loci (4 tri- and 2 di-nucleotide loci) using primers developed specifically for this species and known to give dependable banding patterns (Shaw 1997). Specific loci were polymerase chain reaction (PCR)-amplified using dedicated primers, one of which was end-labelled with ${ }^{32} \mathrm{P}$, and the resulting products run out on a $6 \%$ denaturing polyacrylamide sequencing gel. Gels were exposed to autoradiographic film for 12 to $48 \mathrm{~h}$, and the film was then developed to visualise the genotype banding patterns for each individual, Band (allele) sizes were determined against M13 sequences run on the same gel (details in Shaw 1997).

Results and discussion. High yields of good quality total DNA were obtained from all embryos, and the DNA amplified successfully for all loci in most samples. Banding patterns were clear and unambiguous (Fig. 1). The number of different alleles detected. within single egg strings ranged from 3 to 6 per locus (Table 1). The samples of egg string surface vielded only very small amounts of DNA which gave confusing multi-band patterns after amplification (lanes 'ss' in Fig 1)

The results show that good quality fingerprints/ multi-locus genotypes can be obtained from prehatching embryos in squid using dedicated primers. Unfortunately, the possibility of determining the genotype of the female depositing each string from the DNA extracted from the string surface could not be realised due to the multi-band patterns arising from amplification of this tissue. It is, however, possible with 6 such variable loci to reconstruct a putative female genotype that is not inconsistent with the observed genotype distributions amongst the offspring, making the usual Mendelian assumptions of 1 allele per genotype coming from the iemale and only 2 alleles in total present in the female. The proposed putative female and consequently the possible male genotypes contributing to each brood are indicated in Table 1 Although it is not possible to verify statistically the exact number and genotypic identities of the males contributing to the fertilisation of the embryos in each string, it is possible to make several important deductions about possible reproductive strategies giving rise to these brood samples:

First, strings 1 and 2 from egg mass $A$ ( $A 1$ and A2 in Table 1) were almost certainly spawned by the same female. In contrast, strings 1 and 2 from egg mass $B$ (B1 and $B 2$ in Table 1) were definitely spawned by different females (no common allele at locus Lfor3).

Second, since single egg strings are extruded complete by an individual female, the finding of 6 different alleles at 2 single loci (Lfor 2 and Lfor 3 in strings A 1 and A2 - see Fig. 1) within the embryos of a single string confirms the occurrence of multiple paternity in this species of squid: 2 alleles must come from the female, the remaining 4 alleles coming from between 2 (heterozygous) and 4 (homozygous) males.

Third, this evidence indicates that both strings 1 and 2 from egg mass A resulted from the mating of 1 female with the same 2 males; 2 embryos out of the 10 tested in each string being the progeny of 1 of the males (indicated in Table 1). String 1 in mass B results from the mating of a different female with possibly 1 (there are no more than 4 alleles at any locus) but probably also more than 1 male (skewed distribution of alleles in the postulated paternal contribution: the postulated maternal genotype is based on the expectation of more even allele distributions - Table 1). Finally, string 2 in mass $B$ results from the mating of a third female with at least 2 males: although there are no more than 4 alleles present within the brood at any 1 locus, the only possible consistent maternal genotype indicates at least 3 different paternal alleles to be present at 5 out of the 6 loci (although consistent genotypes of 2 males cannot be deduced, so only the combined paternal alleles are indicated in Table 1).

The most important conclusion from these results is that, unquestionably in at least one brood, multiple

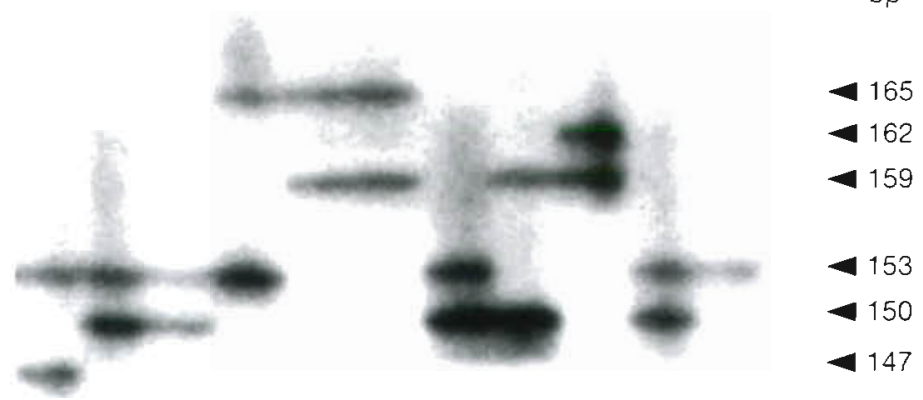

$\begin{array}{llllllllllll}1 & 2 & 3 & 4 & 5 & 6 & 7 & 8 & 9 & 10 & \text { ss } & \text { Ss }\end{array}$
Fig. 1 Loligo forbesi. Autoradiograph showing banding patterns for brood A1 at locus Lfor2. Embryos 1 to 1.0, and samples of egg string skin (ss) are marked; the brood clearly exhibits 6 different size alleles ranging from 147 to 165 base paurs (bp) 
Table 1. Loligo forbesi. Genotypes of embryos from 4 egg strings, across 6 microsatellite loci. Allele designations are size in base paurs $(-t-=$ not scored) Possible maternal/paternal multı-locus genotypes deduced from allele complements are indicated for each brood (males for $\mathrm{A} 1$ and $\mathrm{A} 2$ are the same, +: offspring of male 2; paternal alleles, not genotypes are shown for B2; see text) $n$. alleles that are known to be masked by a 'null allele' when using a different set of primers (Shaw 1997) to amplify Lfor $1^{\circ}$, so are scored as different alleles. No other loci exhibited null alleles

\begin{tabular}{|c|c|c|c|c|c|c|c|}
\hline & \multicolumn{6}{|c|}{ Locus } \\
\hline & & Lfor $1^{\circ}$ & Lfor 2 & Lfor3 & Lfor 4 & Lfor5 & Ltor6 \\
\hline \multicolumn{8}{|c|}{ String A1 } \\
\hline \multirow{10}{*}{ Embryo } & $1+$ & $139^{n} / 175$ & $147 / 153$ & $114 / 171$ & $203 / 215$ & $110 / 110$ & $113 / 117$ \\
\hline & 2 & $139 / 148$ & $150 / 153$ & $162 / 171$ & $203 / 203$ & $108 / 110$ & $93 / 119$ \\
\hline & 3 & $139 / 148$ & $150 / 153$ & $162 / 171$ & $203 / 209$ & $108 / 126$ & $93 / 113$ \\
\hline & 4 & $139 / 175$ & $153 / 165$ & $120 / 171$ & $203 / 209$ & $110 / 114$ & $107 / 113$ \\
\hline & 5 & $139 / 148$ & $159 / 165$ & $120 / 165$ & $203 / 209$ & $110 / 114$ & $107 / 113$ \\
\hline & 6 & $139 / 175$ & $159 / 165$ & $120 / 165$ & $203 / 209$ & $108 / 126$ & $93 / 113$ \\
\hline & 7 & $139 / 148$ & $150 / 153$ & $162 / 171$ & $203 / 209$ & $110 / 114$ & $107 / 113$ \\
\hline & 8 & $139^{17} / 175$ & $150 / 159$ & $162 / 165$ & $209 / 215$ & $110 / 114$ & $107 / 113$ \\
\hline & $9+$ & $139^{n / 148}$ & $159 / 162$ & $165 / 174$ & $203 / 203$ & $110 / 126$ & $107 / 119$ \\
\hline & 10 & $139 / 148$ & $150 / 153$ & $162 / 171$ & $203 / 215$ & $114 / 126$ & $107 / 119$ \\
\hline \multicolumn{2}{|c|}{ Female? } & $148 / 175$ & $153 / 159$ & $165 / 171$ & $203 / 215$ & $110 / 126$ & $113 / 119$ \\
\hline \multicolumn{2}{|l|}{ Male 1? } & $139^{n} / 139$ & $150 / 165$ & $120 / 162$ & $203 / 209$ & $108 / 114$ & $93 / 107$ \\
\hline \multicolumn{2}{|l|}{ Male 2?+ } & $139^{n} / 139^{n}$ & $147 / 162$ & $114 / 174$ & $203 / 203$ & $110 / 110$ & $107 / 117$ \\
\hline \multicolumn{8}{|c|}{ String A2 } \\
\hline \multirow[t]{10}{*}{ Embryo } & 1 & $139 / 148$ & $150 / 153$ & $162 / 165$ & $203 / 209$ & $110 / 114$ & $93 / 119$ \\
\hline & 2 & $139^{n} / 148$ & $159 / 165$ & $120 / 165$ & $203 / 203$ & $114 / 126$ & $107 / 113$ \\
\hline & $3+$ & $139^{n / 175}$ & $147 / 153$ & $114 / 171$ & $203 / 215$ & $110 / 110$ & $113 / 117$ \\
\hline & 4 & $139 / 175$ & $153 / 162$ & $120 / 171$ & $203 / 215$ & $114 / 126$ & $-1-$ \\
\hline & 5 & $139 / 175$ & $159 / 165$ & $120 / 165$ & $209 / 215$ & $110 / 114$ & $107 / 119$ \\
\hline & 6 & $139 / 175$ & $150 / 159$ & $162 / 165$ & $209 / 215$ & $110 / 114$ & $107 / 119$ \\
\hline & $7+$ & $139^{n} / 175$ & $153 / 162$ & $171 / 174$ & $203 / 215$ & $110 / 126$ & $113 / 117$ \\
\hline & 8 & $139^{n} / 148$ & $153 / 165$ & $120 / 171$ & $203 / 203$ & $08 / 126$ & $93 / 113$ \\
\hline & 9 & $139 / 148$ & $150 / 153$ & 1621 & 203 & 26 & $107 / 119$ \\
\hline & 10 & $139^{n} / 175$ & $159 / 1$ & 120 & 203 & 11 & $93 / 119$ \\
\hline \multicolumn{2}{|l|}{ Female? } & $148 / 175$ & $153 / 159$ & $165 / 171$ & $203 / 215$ & $110 / 126$ & $113 / 119$ \\
\hline \multicolumn{8}{|c|}{ String B1 } \\
\hline \multirow{10}{*}{ Embryo } & 1 & $142 / 145$ & $147 /$ & $144 / 183$ & 212 & $110 / 116$ & $109 / 109$ \\
\hline & 2 & $142 / 145$ & $147 / 150$ & $153 / 183$ & $212 / 215$ & $110 / 116$ & $113 / 113$ \\
\hline & 3 & $142 / 169$ & $147 / 150$ & $144 / 183$ & $212 / 215$ & $110 / 116$ & $109 / 109$ \\
\hline & 4 & $151 / 169$ & $147 / 150$ & $153 / 183$ & $203 / 212$ & $110 / 116$ & $109 / 109$ \\
\hline & 5 & $145 / 151$ & $147 / 150$ & $144 / 183$ & $203 / 212$ & $110 / 116$ & $109 / 109$ \\
\hline & 6 & $142 / 169$ & $147 / 150$ & $144 / 183$ & $212 / 215$ & $110 / 116$ & $109 / 109$ \\
\hline & 7 & $142 / 169$ & $150 / 156$ & $-1-$ & $-1-$ & $116 / 116$ & $109 / 109$ \\
\hline & 8 & $142 / 169$ & $147 / 150$ & $153 / 183$ & $212 / 215$ & $10 / 116$ & $109 / 109$ \\
\hline & 9 & $142 / 169$ & $147 / 150$ & 144 & $212 / 215$ & $10 / 116$ & $113 / 113$ \\
\hline & 10 & $151 / 169$ & $150 / 1$ & $153 / 171$ & $203 / 215$ & 110 & $109 / 113$ \\
\hline \multirow{2}{*}{\multicolumn{2}{|c|}{$\begin{array}{l}\text { Female? } \\
\text { Male? }\end{array}$}} & $145 / 169$ & $150 / 150$ & $144 / 153$ & $203 / 212$ & $116 / 116$ & $109 / 113$ \\
\hline & & $142 / 151$ & $147 / 156$ & $171 / 180$ & $212 / 215$ & $110 / 116$ & $109 / 113$ \\
\hline \multicolumn{8}{|c|}{ String B2 } \\
\hline \multirow[t]{10}{*}{ Embryo } & 1 & $166 / 166$ & $147 / 153$ & $150 / 174$ & $215 / 218$ & $104 / 120$ & $93 / 111$ \\
\hline & 2 & $145 / 166^{n}$ & $147 / 153$ & $150 / 174$ & $218 / 221$ & $112 / 120$ & $93 / 93$ \\
\hline & 3 & $145 / 145$ & $147 / 153$ & $150 / 168$ & $203 / 203$ & $112 / 120$ & $109 / 111$ \\
\hline & 4 & $145 / 145$ & $150 / 150$ & $-1-$ & $-1-$ & $104 / 104$ & $93 / 101$ \\
\hline & 5 & $166 / 166$ & $150 / 162$ & $156 / 174$ & $203 / 215$ & $112 / 120$ & $93 / 109$ \\
\hline & 6 & $145 / 145$ & $150 / 153$ & $-1-$ & $-/-$ & $112 / 120$ & $109 / 109$ \\
\hline & 7 & $166 / 166$ & $150 / 162$ & $156 / 168$ & $215 / 218$ & $112 / 120$ & $93 / 111$ \\
\hline & 8 & $145 / 145$ & $150 / 162$ & $156 / 168$ & $203 / 221$ & $112 / 120$ & $93 / 111$ \\
\hline & 9 & $145 / 145$ & $147 / 153$ & $150 / 174$ & $203 / 221$ & $-1-$ & $93 / 111$ \\
\hline & 10 & $145 / 166$ & $147 / 150$ & $156 / 168$ & $218 / 221$ & $-1-$ & $93 / 109$ \\
\hline \multirow{2}{*}{\multicolumn{2}{|c|}{$\begin{array}{l}\text { Female? } \\
\text { Males? }\end{array}$}} & $145 / 166$ & $147 / 150$ & $168 / 174$ & $203 / 218$ & $104 / 112$ & $93 / 109$ \\
\hline & & $\begin{array}{c}145,166 \\
166^{n}\end{array}$ & $\begin{array}{c}150,153 \\
162\end{array}$ & 150,156 & $\begin{array}{c}203,215 \\
221\end{array}$ & $\begin{array}{c}104,109 \\
120\end{array}$ & $\begin{array}{r}93,101 \\
109,111\end{array}$ \\
\hline
\end{tabular}

paternity occurs during mating of the squid Loligo forbesi. This result strongly implies that mating behaviour in this species, although not observed directly, involves the sort of competitive behaviour between males described for other loliginids (studies cited in Hanlon \& Messenger 1996). In addition, the recognition of 2 different female genotypes from adjacent strings within egg masses, genetically confirms observations that females may lay their egg strings within exist. ing egg masses depositied by other females, as described for Loligo vulgaris reynaudii (Sauer \& Smale 1993) and Loligo opalescens (Fields 1965, Cousteau \& Diole 1973).

The application of DNA fingerprinting to cephalopod reproductive ecology has reached the demonstration stage. Many more independent loci $(>20)$ would be needed to confirm statistically the full- or half-sib relationships of embryos within single strings and, therefore, the absolute number of males contributing to the fertilization of the eggs from a single female. However, molecular genetic methods provide clear evidence for the first time that male competition at mating in cephalopods does potentially result in multiple paternity of the offspring of a single female. Future application of these techniques in conjunction with facilities for controlled captive manipulation of matings being developed ( $R$. Hanlon pers. comm.) will allow testing of any link between alternative male mating strategies (see Hanlon \& Messenger 1996) and the bimodal size-at-maturity distributions observed in male loliginids (Boyle et al. 1995).

Acknowledgements. We gratefully acknowledge the assistance and advice of colleagues in Aberdeen, Graham Pierce, Martin Collins, Stuart Piertney, Joanne Murphy and Linda Key; Malcolm Smale, Warwick Sauer and Mike Roberts in South Africa for the opportunity to view their underwater video of the mating behaviour of Loligo vulgaris reynaudii; and Roger Hanlon for stimulating this new area of cephalopod biology. This work was funded under EC contract No AIR 1-CT92-0573. 


\section{LITERATURE CITED}

Archer J (1988) The behavioural biology of aggression. Cambridge University Press, Cambridge

Arnold JM (1984) Cephalopods. In: Tompa AS, Verdonck NH, van den Biggelaar (eds) Mollusca, Vol 7: Reproduction Academic Press, London, p 419-453

Birkhead TR (1994) Enduring sperm competition. J Avian Biol $25: 167-170$

Boyle PR (1990) Cephalopod biology in the fisheries context. Fish Res 8:303-321

Boyle PR, Boletzky SV (1996) Cephalopod populations: definition and dynamics. Philos Trans R Soc Lond B Biol Sci 351:985-1002

Boyle PR, Pierce GJ (eds) (1994) Fishery biology of north east Atlantic squid. Fish Res 21:1-310

Boyle PR, Pierce GJ, Hastie LC (1995) Flexible reproductive strategies in the squid Loligo forbesi. Mar Biol 121: 501-508

Collins MA, Pierce GJ, Boyle PR (1997) Population indices of reproduction and recruitment in Loligo forbesi (Cephalopoda: Loliginidae) in Scottish and Irish waters. J Appl Ecol $34: 778-786$

Cousteau JY, Diole P (1973) Octopus and squid. The soft intelligence. Cassell, London

Estoup A, Scholl A, Pouvreau A, Solignac M (1995) Monoandry and polyandry in bumble bees (Hymenoptera Bombinae) as evidenced by highly variable microsatellites. Mol Ecol 4:89-93

Fields WG (1965) The structure, development, food relations, reproduction, and life history of Loligo opalescens Berry.

Editorial responsibility: Otto Kinne (Editor),

Oldendorf/Luhe, Germany
Calif Fish Game Fish Bull 131:1-108

Hanlon RT (1996) Evolutionary games that squids play: fighting, courting. sneaking and mating behaviours used for sexual selection in Loligo pealei. Biol Bull (Woods Hole) 191:309-310

Hanlon RT, Messenger JB (1996) Cephalopod behaviour. Cambridge University Press, Cambridge

Mangold K (1987) Reproduction. In: Boyle PR (ed) Cephalopod life cycles, Vol II. Comparative reviews. Academic Press, London, p 157-200

Morin PA, Wallis J, Moore JJ, Woodruff DS (1994) Paternity exclusion in a community of wild chimpanzees using hypervariable simple sequence repeats. Mol Ecol 3:469-478

Packer C, Gilbert DA, Pusey AE, O'Brien SJ (1991) Kinship and cooperation in African lions: a molecular genetic analysis. Nature 351:562-565

Parker GA (1970) Sperm competition and its evolutionary consequences in the insects. Biol Rev 45:525-567

Pemberton JM, Albon SD, Guiness FE, Clutton-Brock TH, Dover GA (1992) Behavioural estimates of male mating success tested by DNA fingerprinting in a polygynous mammal. Behav Ecol 3:66-75

Pierce GJ, Boyle PR. Hastie LC, Key L (1994) The life history of Loligo forbesi in Scottish waters. Fish Res 21:17-41

Sauer WHH, Smale MJ (1993) Spawning behaviour of Loligo vulgaris reynaudis in shallow coastal waters of the southeastern Cape, South Africa. In: Okutani $T_{1}$ O'Dor RK, Kubodera $T$ (eds) Recent advances in cephalopod fisheries biology. Tokai University Press, Tokyo, p 489-498

Shaw PW (1997) Polymorphic microsatellite DNA markers in the veined squid Loligo forbesi. Mol Ecol 6:297-298

Submitted: June 16, 1997; Accepted: October 6, 1997 Proofs received from author(s): November 26, 1997 